\title{
Role of $\mathrm{N}$-acetylcysteine in the management of COPD
}

\author{
Anna M Sadowska \\ J Verbraecken \\ $K$ Darquennes \\ WA De Backer
}

Department of Pulmonary Medicine, University of Antwerp,

Antwerp, Belgium
Correspondence:Anna M Sadowska Department of Pulmonary Medicine, University of Antwerp,

Universiteitsplein I, 2610 Antwerp, Belgium

Tel +323820 2589

Fax +323820 2574

Email anna.sadowska@ua.ac.be

\begin{abstract}
The importance of the underlying local and systemic oxidative stress and inflammation in chronic obstructive pulmonary disease (COPD) has long been established. In view of the lack of therapy that might inhibit the progress of the disease, there is an urgent need for a successful therapeutic approach that, through affecting the pathological processes, will influence the subsequent issues in COPD management such as lung function, airway clearance, dyspnoea, exacerbation, and quality of life. N-acetylcysteine (NAC) is a mucolytic and antioxidant drug that may also influence several inflammatory pathways. It provides the sulfhydryl groups and acts both as a precursor of reduced glutathione and as a direct reactive oxygen species (ROS) scavenger, hence regulating the redox status in the cells. The changed redox status may, in turn, influence the inflammation-controlling pathways. Moreover, as a mucolytic drug, it may, by means of decreasing viscosity of the sputum, clean the bronchi leading to a decrease in dyspnoea and improved lung function. Nevertheless, as successful as it is in the in vitro studies and in vivo studies with high dosage, its actions at the dosages used in COPD management are debatable. It seems to influence exacerbation rate and limit the number of hospitalization days, however, with little or no influence on the lung function parameters. Despite these considerations and in view of the present lack of effective therapies to inhibit disease progression in COPD, NAC and its derivatives with their multiple molecular modes of action remain promising medication once doses and route of administration are optimized.
\end{abstract}

Keywords: $\mathrm{N}$-acetylcysteine, chronic obstructive pulmonary disease

\section{Management issues in COPD}

\section{Lung function, dyspnoea and quality of life}

Chronic obstructive pulmonary disease (COPD) is a condition defined as a disease state characterized by airflow limitation that is not fully reversible. The airflow limitation is usually progressive and is associated with an abnormal inflammatory response of lungs to noxious particles or gases, primarily caused by cigarette smoking (Celli et al 2004). In Europe, COPD is ranked as the third most common cause of death (Pauwels et al 2001).

The lung function and consequently patient quality of life worsens as disease progresses (Seemungal et al 1998; Hogg 2004). The standard way of assessing the progression of COPD (Burrows and Earle 1969) is an annual decline in forced expiratory volume in one second $\left(\mathrm{FEV}_{1}\right)$, which is considered to be the best single correlate of mortality (Celli et al 2004) and is used as the main parameter in the evaluation of many other COPD aspects. In comparison with the normal subject where the $\mathrm{FEV}_{1}$ decline reaches 20-30 mL/year, in COPD patients it reaches $60 \mathrm{~mL} /$ year (Anthonisen et al 1994). This accelerated decline in lung function is closely associated with an increased number of neutrophils in the sputum (Stanescu et al 1996) and hence with higher level of airway inflammation. This, on the other hand, is proportional to the rise in the colonizing bacterial load as well as its changes (Wilkinson et al 2003). 
Cross-sectional studies have shown that quality of life deteriorates as lung function declines (Stahl et al 2005). Some groups, however, reported that the health status and health-related quality of life (HRQOL) do not strongly correlate with the lung function parameters such as $\mathrm{FEV}_{1}$ (Antonelli-Inc et al 2003), but relate more to exercise performance, mobility, and mortality (Jones et al 1989; Fan et al 2002). Since any improvement in physical performance relates to an improvement in quality of life scores and dyspnoea perception (Verrill et al 2005), the limitation of a functional status is considered very highly predictive of survival (ZuWallack et al 2004). Furthermore, dyspnoea correlates more closely with an impact on HRQOL than $\mathrm{FEV}_{1}$. Therefore, dyspnoea and HRQOL have become an important focus for therapy as dyspnoea is the predominant complaint for which patients with COPD seek medical attention (Hajiro et al 1999).

\section{Exacerbations}

Patients with COPD are prone to periodic acute exacerbations (AE) of their disease with worsening of the respiratory symptoms and inflammatory parameters (Drost et al 2005). The frequency of these exacerbations varies, depending on the definition and severity (Wedzicha and Donaldson 2003). AE contributes to a diminished HRQOL and consequently to the reduced health status, frequent hospitalizations, and eventually increased morbidity (Donaldson et al 2002). Moreover, the exacerbations lead to the increased healthcare costs with exacerbations associated with a hospitalization accounting for $90 \%$ of the total costs of exacerbations (Oostenbrink and Rutten-van Molken 2004).

Furthermore, the number of exacerbations per year correlates with disease severity (Siafakas et al 1995). An increased frequency of these episodes may hasten disease progression and accelerate the decline in the lung function since a physiologic recovery after an exacerbation is usually incomplete resulting in the decrease in quality of life and a tendency to future exacerbations (Donaldson et al 2002). Also more pronounced physiologic changes during AE are related to a longer exacerbation recovery time. Additionally, it has been reported that lung function together with health status are the most important risk factors for the re-admission that also relate to the psychological status of the patients (Gudmundsson et al 2005). Therefore the prevention of an acute exacerbation and improving the health status should be considered as one of the most important therapeutic targets.

\section{Oxidative stress and inflammation}

There is increasing evidence that an oxidant/antioxidant imbalance, in favor of oxidants, occurs in COPD (Rahman et al 1996; MacNee 2000). The main reason for this is cigarette smoke which is a complex mixture of more than 4700 chemical compounds, including high concentrations of free radicals and other oxidants (Church and Pryor 1985). Components of the lung matrix (eg, collagen, elastin) can be directly damaged by the cigarette smoke (Cantin and Crystal 1985). In the breath, the oxidants generated by cigarette smoking or released from leukocytes and epithelial cells, are increased in stable patients and those with an acute exacerbation of COPD (Dekhuijzen et al 1996; Maziak et al 1998). There is also evidence that a systemic oxidative stress is present in the COPD patients. This is reflected by an increased production of superoxide anion from the peripheral blood neutrophils in stable (Noguera et al 1998) and exacerbated COPD patients (Rahman et al 1996). Oxidative stress is inextricably linked to the inflammatory response. It becomes clear that the inflammatory process potentiates as COPD progresses (Hogg 2004) and exerts damage which is irreversible. This damage involves a complex remodeling process resulting in emphysema and fibrosis of the small airways. Tobacco smoking is not only a major source of the oxidants but is also a major factor initiating the local inflammatory response (Churg et al 2002).

During acute exacerbation of COPD (AE), except for changes in the overall health status, there are differences observed in the inflammatory and oxidative stress status of the patients. The increased number of inflammatory cells and the accompanying elevated cytokine levels in stable COPD patients tend to rise even further during AE (Drost et al 2005), reflecting the worsening of the underlying chronic inflammation in the lungs. These acute-upon-chronic episodes augment the damage exerted by chronic processes and may diminish the chances of full recovery.

The management points in COPD are shown in Figure 1.

\section{Role of mucolytics}

For patients suffering from COPD, asthma, and cystic fibrosis, mucus hypersecretion is considered to be a risk factor for increased morbidity. While chronic mucus hypersecretion may not impair the lung function of the healthy individual, in a case of obstructive lung disorder, excessive mucus production accompanied by an inadequate mucus clearance may further hinder the air passage by clogging the already obstructed airways (Jeffery and Li 1997). The mucus is a 


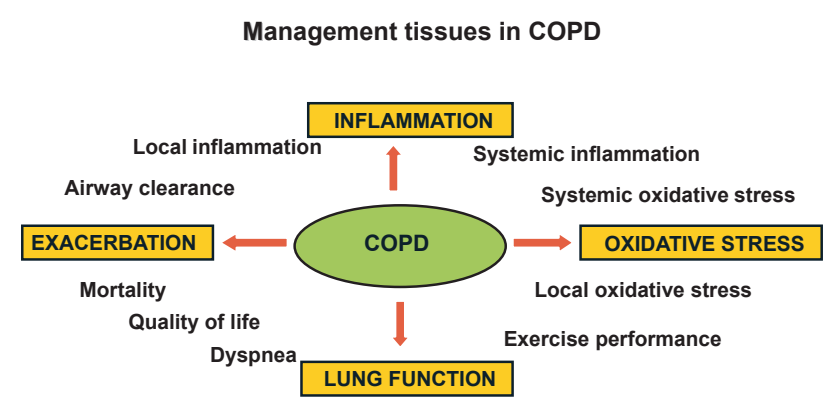

Figure I Management issues in COPD.

complex mixture of proteins, lipids, water, and electrolytes (Snider et al 1984; Robinson et al 1989) that, under normal conditions, maintains the moisture of the airway epithelium. It is produced by goblet, mucous, and serous cells (Lundgren and Shelhamer 1990) and stored until a secretory signal is given. The mucus secretion may be stimulated by mediators produced by macrophages, lymphocytes, and epithelium (Cohan et al 1991; Gollub et al 1992). Furthermore, in the view that neutrophils are the key cells in COPD, there is emerging evidence that they play a key role in epidermal growth factor receptor (EGFR)-mediated mucin production through releasing tumor necrosis factor-alpha (TNF- $\alpha$ ) and hence inducing EGFR expression (Takeyama et al 1999; Kim and Nadel 2004). Moreover, the differentiation of the mucus cells as well as secretion of the mucus from airway glands are induced by neutrophil elastase (Breuer et al 1987).

Nevertheless, by entrapping and removing foreign materials, the mucus forms a basic defense system of the respiratory system. In the large airways, mucus hypersecretion causes coughing and sputum production. In the peripheral airways, because of the smaller diameter, the formed mucus plugs are difficult to remove and may block the peripheral airway completely. This, in turn, may result in gas trapping with increased total lung capacity (TLC) and decreased forced vital capacity (FVC). In COPD, mucus hypersecretion is associated with disease exacerbation (Poole and Black 2003), accelerated decline in $\mathrm{FEV}_{1}$ (Vestbo et al 1996) and inflammatory cell infiltration (Wedzicha and Donaldson 2003). Moreover, the remaining sputum hinders the accessibility of inhaled medication to the peripheral airways. Therefore the mucus clearance and sterility maintenance are of importance in COPD. There is a large number of medications available that are meant to change the properties of airway secretion or block its production or release, or both. The mucolytics are responsible for the disruption of the mucous gel, generally by altering the degree of the cross-linking or the interactions between molecules in the gel. They include N-acetylcysteine (NAC) and related compounds, dornase- $\alpha, \mathrm{F}$-actin de-polymerizing agents and nondestructive mucolytics, like hypertonic saline and oligosaccharide agents and were previously reviewed (King and Rubin 2002).

Current treatments for COPD are symptomatic and focus on the bronchodilatation. No effective medication currently exists that may influence the progress of the disease. Therefore, mucolytics like NAC may form an interesting therapeutic approach. Classical mucolytics, like NAC and other thiol reducing agents, degrade the three-dimensional network that forms the mucus by reducing the disulphide bonds (S-S) to a sulfhydryl (SH) bond (-SH) that no longer participates in the cross-linking. They may act on the mucus elasticity and viscosity as well as modulate its production and secretion (Livingstone et al 1990; King and Rubin 2002). NAC has been reported to reduce the viscosity of sputum in both cystic fibrosis and COPD, facilitating the removal of pulmonary secretions (Ventresca et al 1989). Moreover, by maintaining the airway clearance, it prevents bacterial stimulation of mucin production and hence mucus hypersecretion (Adler et al 1986).

NAC however, has also its disadvantages concerning its accessibility of the peripheral airways and risk of bronchospasm in hyperreactive patients. Nevertheless, the superiority of NAC over the other mucolytics may be in its anti-inflammatory and antioxidant properties and its mucolytic actions.

\section{NAC: pharmacology and pharmacokinetics}

$\mathrm{N}$-acetylcysteine is a thiol compound which has a chemical formula $\mathrm{C}_{5} \mathrm{H}_{9} \mathrm{NO}_{3} \mathrm{~S}$ and a molecular weight of 163.2. It is rapidly absorbed following an oral dose of $600 \mathrm{mg}$ with a peak of $4.6 \mu \mathrm{M}$ after $60 \mathrm{~min}$ (Tsikas et al 1998). The plasma half-life has been reported to be 2.5 hours and no NAC is detectable 10-12 hours after administration (De Caro et al 1989). It has been estimated that the oral bioavailability of the intact NAC molecule was about 10\% (Borgstrom and Kagedal 1990). Following an oral dose, the majority of NAC is metabolized into another compound since accompanying increase in nonprotein and protein $\mathrm{SH}$ groups were found in plasma (Cotgreave, Berggren, et al 1987; De Caro et al 1989). Normalized maximal plasma concentration was reported to be significantly higher after a $600 \mathrm{mg}$ dose 
than after a $200 \mathrm{mg}$ dose. Moreover, increasing the dose also increased NAC bioavailability and time for maximal plasma concentration (Borgstrom and Kagedal 1990). Yet, higher concentration in plasma may be achieved after the intravenous administration (Prescott et al 1989; Crouch and Rusho 2005). During absorption, NAC is rapidly metabolized to cysteine, whose thiol group has reducing and antioxidant properties and which is a direct precursor of the glutathione. Because of its ability to reduce disulphide bounds, NAC is widely used to reduce viscosity and elasticity of the mucus (Aruoma et al 1989). Moreover, NAC has the potential to interact directly with oxidants such as hydrogen peroxide, hydroxyl radical, and hypochloric acid (Aruoma et al 1989). To exert some effects in the lungs, concentration of NAC or its derivatives have to be sufficiently elevated in bronchial epithelium or in epithelial lining fluid. Nevertheless, no NAC was found in bronchoalveolar lavage fluid (BALF) after 2 weeks of NAC intake (200 mg three times daily [tid]) by healthy volunteers (Cotgreave, Eklund, et al 1987).

\section{Antioxidant properties}

As a source of SH groups in cells, NAC can stimulate glutathione (GSH) synthesis and play a role in the detoxification (Kelly 1998) and play an important role in the antioxidant defense. However, when administered orally it fails to reach the desired concentration in the lungs as $600 \mathrm{mg} /$ day did not alter cysteine and glutathione in BALF of healthy volunteers. However, it significantly increased free and total plasma glutathione and cysteine (Cotgreave, Eklund, et al 1987). When $600 \mathrm{mg}$ was administered to COPD patients an increase in plasma cysteine was observed with no difference in GSH levels. The higher dose was necessary (600 mg tid) in order to increase GSH levels in COPD patients (Bridgeman et al 1994). This observation may suggest that under the condition of permanent oxidative stress, $600 \mathrm{mg}$ may not be sufficient to replenish the diminished GSH content. NAC can also act as direct scavenger of free radicals such as $\mathrm{OH}$ and $\mathrm{H}_{2} \mathrm{O}_{2}$ and $\mathrm{O}_{2}$ (Benrahmoune et al 2000) and it can protect against $\mathrm{O}_{2}$ toxicity in the lung (Erzurum et al 1993).

\section{Anti-inflammatory properties}

Inflammatory response is strongly influenced by redox-sensitive nuclear transcription factor- $\kappa \mathrm{B}(\mathrm{NF}-\kappa \mathrm{B})$ which regulates a variety of pro-inflammatory genes, and hence modulates the inflammatory response (Desaki et al 2000). In vitro studies showed that a decrease in several inflammatory mediators was related to NF- $\mathrm{KB}$ activity inhibition (Lappas et al 2003).
Due to the fact that NAC modulates the cellular redox status, it can affect several pathways leading to decrease in NF- $\kappa B$ activity (Hutter and Greene 2000). Namely, NAC may affect thioredoxin and glutaredoxin expression which form other parts of ubiquitously expressed thiol-reducing system next to glutathione. Thioredoxin increases DNA binding of NF- $\kappa \mathrm{B}$ by reducing cysteine of the p50 subunit (Matthews et al 1992) while glutaredoxin by sensing the changes in the redox state of GSH/GSSG may be involved in altering signal transduction pathways resulting in biological responses modulation (Song et al 2002). By decreasing the release of thioredoxin and glutaredoxin, NAC may attenuate NF- $\kappa \mathrm{B}$ binding to DNA (Hoppe et al 2003; Nakamura H et al 1996) resulting in an impaired inflammatory response (Peltoniemi et al 2004). Except from its effects on transcription factor NF- $\kappa \mathrm{B}, \mathrm{NAC}$ influences several signaling pathways such as p38, ERK1/2, SAPK/JNK, c-Jun, and c-Fos, among others (Wuyts et al 2003). Clinical application of NAC in different disorders as well as its molecular actions have been reviewed previously (Wuyts et al 2003; Zafarullah et al 2003).

\section{Role of NAC in COPD}

\section{Lung function}

$\mathrm{N}$-acetylcysteine was reported to improve the lung function when administered for a longer period of time. Namely, Pela and colleagues (1999) reported a significant improvement in $\mathrm{FEV}_{1}$ and maximal expiratory flow at $50 \%$ of forced vital capacity $\left(\mathrm{MEF}_{50}\right)$ after 6 month treatment of stable COPD patients with NAC (600 mg/day). It supported the study of Aylward and colleagues (1980) who observed an improvement from 25 to $30 \% \mathrm{FEV}_{1}$ (\% predicted) in the NACtreated group during the 4 weeks study period (Aylward et al 1980). On the other hand, several groups did not find any changes in $\mathrm{FEV}_{1}$ and $\mathrm{FVC}$ although some reduction of hyperinflation was obtained (Decramer et al 2005; van Overveld et al 2005).

\section{Exacerbation}

As far as exacerbations are concerned, in a recent literature review, Poole and Black (2003) found that regular use of mucolytics resulted in a significant reduction of exacerbations by 0.07 exacerbation/month and reduction of illness days of 0.56 days/month. Moreover, the study of Gerrits and colleagues (2003) found the correlation between the dose of NAC and the number of hospitalizations due to exacerbation. They concluded that NAC may decrease the risk of hospitalizations 
Table I Effects of NAC on clinical COPD outcomes

\begin{tabular}{|c|c|c|c|c|c|c|c|c|c|c|}
\hline & Dose & Number & $\begin{array}{l}\text { Study } \\
\text { period }\end{array}$ & FEV & QOL & Dyspnea & Exacerbation & $\begin{array}{l}\text { Hospitalisa- } \\
\text { tion / } \\
\text { sick days }\end{array}$ & $\begin{array}{l}\text { Side } \\
\text { effects }\end{array}$ & Ref \\
\hline $400 \mathrm{mg}$ & $200 \times 2$ & 259 & 6 months & - & - & - & $\Downarrow$ & $\Downarrow$ & $\mathrm{NO}$ & 12 \\
\hline \multirow[t]{8}{*}{$600 \mathrm{mg}$} & $600 \times 1$ & 248 & 2 months & - & - & $\Downarrow$ & - & - & $23 \%^{x}$ & 93 \\
\hline & $600 \times 1$ & 523 & 3 years & NS & NS & - & $\Downarrow \#$ & - & NO & 29 \\
\hline & $600 \times 1$ & 169 & 6 months & & $\begin{array}{l}\text { Improve- } \\
\text { ment in } \\
\text { cough } \\
\text { severity }\end{array}$ & - & $\Downarrow$ & $\Downarrow$ & NS & 73 \\
\hline & $600 \times 1$ & 20 & 10 weeks & NS & - & - & - & - & NO & 97 \\
\hline & $300 \times 2$ & 116 & 6 months & - & - & - & $\Downarrow(\mathrm{NS})$ & $\Downarrow$ & NO & 79 \\
\hline & $200 \times 3$ & 180 & 5 months & - & - & - & $\Downarrow(\mathrm{NS})$ & & NS & 1 \\
\hline & $200 \times 3$ & 526 & 6 months & - & - & - & NS & $\Downarrow$ & $\begin{array}{l}\text { Well- } \\
\text { tolerated }\end{array}$ & 70 \\
\hline & $200 \times 3$ & 121 & 3 months & - & - & - & - & - & $\begin{array}{l}\text { Well- } \\
\text { tolerated }\end{array}$ & 48 \\
\hline 1200 mg & $600 \times 2$ & 153 & 22 weeks & NS & NS & - & $\Downarrow(\mathrm{NS})$ & - & NO & 43 \\
\hline *I800 mg & $600 \times 3$ & 9 & 4 days & - & - & - & - & - & NO & 55 \\
\hline
\end{tabular}

Note: *short duration COPD; \#subgroup without ICS; ${ }^{\times}$percentage of patients suffering from side effects.

Abbreviations: COPD, chronic obstructive pulmonary disease; $\mathrm{FEV}_{\text {, }}$ forced expiratory volume in one second; ICS, inhaled corticosteroid; NAC, N-acetylcysteine; NO, no reported side effects; NS not significantly different from placebo group-not reported; QOL, quality of life.

by about $30 \%$. This reduction however needed minimal dose of $400 \mathrm{mg}$ /day in order to reach protective effect (Gerrits et al 2003). It was also supported by study of Boman and colleagues (1983), who showed a reduction in exacerbation rate of $40 \%$, which was significantly different from $19 \%$ in placebo group. On the other hand, some studies only observed a trend towards a lower exacerbation rate (Parr and Huitson 1987) or no effect at all (Rasmussen and Glennow 1988). Nevertheless, those studies reported a significant reduction in a sick-leave days after 4 and 6 months of NAC treatment. The last large, 3-year study on NAC, the BRONCHUS trial, reported a significant decrease in exacerbation rate only with no concomitant steroid therapy (Decramer et al 2005). The reports on NAC as add-on treatment during an acute exacerbation of COPD are scarce. The study of Black et al showed that the treatment of AE with NAC (600 mg twice daily) did not affect breathlessness, lung function, and oxygen saturation (Black et al 2004).

The mechanisms underlying the reduction in the number of exacerbations as well as the days of illness are not very well described. Because of the fact that no significant increase in GSH level was found in plasma and BALF while using low dose (600 mg daily) higher dosages were necessary (600 mg tid) to obtain sustained effect on the thiols level in plasma, it seems unlikely that the changes induced by lower dose of NAC may alter the exacerbation rate or the course of exacerbations. On the other hand, NAC was reported to influence sputum cytokine level (van Overveld et al 2005) as well as sputum chemoattractant properties (van Overveld et al 2000). Because of the fact that a correlation between exacerbation frequency and sputum IL-6 and IL-8 levels exists (Bhowmik et al 2000), NAC, by acting on baseline level of those cytokines, may play a role in limiting the inflammatory status and hence modulate the exacerbation frequency. Moreover, by decreasing the viscosity of the sputum, it may facilitate the airway clearance and hence influence the course of the exacerbation, since there is a relationship between bacterial colonization and exacerbation frequency and character (Patel et al 2002). Effects of NAC on lung function and exacerbation rate are summarized in Table 1. The results from aforementioned reports indicate that low doses of NAC may have rather low antioxidant potential resulting in insignificant improvement of the lung function and limited influence on the exacerbation rate.

\section{Inflammation and oxidative stress in COPD}

$\mathrm{N}$-acetylcysteine has been reported to influence several factors that are involved in the modulation of the inflammatory response. Namely, NAC decreased the chemoattractant properties of the sputum of COPD patients after 10 month 
treatment (van Overveld et al 2000) and modulated the inflammatory response after 10 weeks of intake (Sadowska et al 2005). Moreover, in healthy volunteers it decreased the formyl-methionyl-leucyl-phenylalanine (fMLP)-stimulated respiratory burst and chemotaxis (Sadowska et al 2006). Furthermore, in the study of Urban and colleagues (1997), NAC improved the phagocytotic ability of neutrophils while decreasing their production of superoxide anion (SA) with no effects on migration already after 14 days of administration in healthy volunteers.

As far as oxidative stress is concerned, NAC decreased the exhaled $\mathrm{H}_{2} \mathrm{O}_{2}$ levels in COPD patients after long-term treatment (Kasielski and Nowak 2001; De Benedetto et al 2005). Moreover, when administered to healthy volunteers, it increased the glutathione peroxidase activity (GPx) after 2 weeks of oral treatment (Urban et al 1997) and increased thiol level after $30 \mathrm{~min}$ and 3 hours after administration (Szkudlarek et al 2004).

It did not, however, influence GSH and cysteine level in BALF and lung tissue (Bridgeman et al 1994).

Furthermore supplementation with NAC $(200 \mathrm{mg} \times 4$ /day for 2 days $+800 \mathrm{mg}$ on the test morning) increased the pre-exercise scavenging activity of healthy volunteer plasma (Sen et al 1994). When administered in higher doses (125 mg/kg) (intravenously) NAC significantly increased GSH content and attenuated its decline during intense intermittent exercise and led to lesser glutathione disulfide (GSSG) formation (Medved et al 2003).

These reports strongly suggest that for effective antiinflammatory and antioxidant action, higher doses are necessary as the low NAC concentration (as also observed in vitro) was not found satisfactory (Sadowska et al 2007). This could be due to pharmacokinetics of NAC and administration route, which is far from optimal as it is unlikely to achieve desired concentration in the lung compartment (Bridgeman et al 1994). The novel route (eg, inhalation) is currently under investigation for both NAC and its derivatives and it is discussed in the last section.

\section{Patient-focused perspectives}

\section{Quality of life}

$\mathrm{FEV}_{1}$ hardly correlates with dyspnoea, which is closely related to the patient's quality of life and which can vary among the patients with the same degree of the airway obstruction (Wolkove et al 1989). Dyspnoea, on the other hand, may reflect more comprehensive information than airway obstruction in patients with COPD and should be taken into account while evaluating the successful treatment. NAC was reported to decrease the dyspnoea in COPD patients in comparison with placebo during the long-term treatment (Aylward et al 1980; Tattersall et al 1984). This may be partly caused by the mucolytic effects of NAC leading to increase in the sputum volume and pourability. Moreover, an improvement in the subjects' clinical state after NAC treatment has been noted (Jackson et al 1984) as well as an improvement of bronchitis-related symptoms (Stey et al 2000) and increase in the patients' well-being (Hansen et al 1994). Furthermore, in study of Pela and colleagues (1999), $65 \%$ of the treated patients reported improvement in quality of life in the NAC group (NAC on top of the current therapy) compared with $29 \%$ in placebo group.

As far as the influence of NAC on physical activity is concerned, it successfully improves the performance on fatiguing exercise when administered in high dosages. Namely, in the study by Matuszczak and colleagues (2005), at the oral dose of $150 \mathrm{mg} / \mathrm{kg}$, NAC delayed handgrip fatigue, increasing task performance by one-third compared with the baseline. Similarly, in the study by Medved and colleagues (2004) (125 mg/kg intravenously), NAC increased time to fatigue. Furthermore, the same dose was reported to inhibit fatigue of human skeletal muscles caused by repetitive, low-frequency electrical stimulation (Reid et al 1994). Moreover, high doses of NAC (600 mg $\times 3 /$ day) prevented the exercise-induced increase in plasma thiobarbituric reactive substances and $\mathrm{O}_{2}$ release and led to improved endurance time (Koechlin et al 2004). It may be suggested that NAC in high doses may act on GSH content replenishment and may increase the task performance and have positive effect on the physical activity and hence quality of life.

\section{Compliance}

The compliance is concerned to be better following the $600 \mathrm{mg} /$ day regimen (Pela et al 1999). For example, in the BRONCHUS study, a compliance of $94 \%$ in the NAC group was observed in comparison with $92 \%$ in the placebo group (Decramer et al 2005). Nevertheless, a lower compliance observed at the regimen of $200 \mathrm{mg}$ tid could be improved, following additional patient instructions (Parr and Huitson 1987).

\section{Tolerability and side-effects}

NAC is generally safe. The oral dose of $600 \mathrm{mg} /$ day or less is usually very well tolerated with no apparent side-effects and no impact on the patient satisfaction (Jackson et al 1984; 
Parr and Huitson 1987; Stey et al 2000). A dose of $1800 \mathrm{mg} /$ day administered for a period of 4 days in COPD patients (Koechlin et al 2004) and for 5-6 weeks in the polycystic ovary syndrome was also well tolerated with no reported side-effects (Fulghesu et al 2002). Nevertheless, some trials mention some gastro-intestinal adverse reactions, which are not significantly different from placebo group and comprise of dyspepsia, diarrhea or heartburn (Aylward et al 1980). In the last study of Matuszczak and colleagues (2005) where $150 \mathrm{mg} / \mathrm{kg}$ of NAC was administered orally, mild reactions were reported in most of the patients (erythema, sweating, altered sensations, gastrointestinal disturbances). Except for gastrointestinal disturbances that persisted up to 4 hours and light-headedness which disappeared after 3 hours, the remaining complaints disappeared $60 \mathrm{~min}$ after indigestion of NAC. The most common side-effects associated with high oral doses are nausea, vomiting, and other gastrointestinal disturbances, and therefore oral administration is contraindicated in persons with active peptic ulcer (Koo et al 1986). On the other hand, at low doses NAC may have a positive influence on the bacterial colonization in gastritis (Huynh et al 2004). Infrequently, anaphylactic reactions after intravenous administration due to histamine release occur and can consist of rash, angioedema, bronchospasm, tachycardia, and changes in blood pressure (Tenenbein 1984).

\section{Cost-effectiveness}

High prevalence of COPD carries with it serious financial consequences. According to the Belgisch Instituut voor Gezondheidseconomie, the costs of COPD increase together with the disease progression amounts to (in $€ /$ year/patient) $2977 €$ for Stage I, $4740 €$ for Stage II, and $8565 €$ for Stage III, and IV (De Backer pers comm).

Disease severity, on the other hand, correlates with the number of exacerbations per year (Siafakas et al 1995). Since exacerbation is one of the important factors facilitating the progression of the disease and brings additional costs to the global expenditure, which are especially high in case of hospitalization or intensive care unit admission (Niederman et al 1999), effective exacerbation prevention could be the major cost-reducing factor.

Grandjean and colleagues (2000) showed that NAC at dose $400 \mathrm{mg} /$ day not only led to a significant reduction in the number of exacerbations but also resulted in a smaller percentage of sick-leave days and lower hospitalization rate, what leads to a direct (NAC treatment, AE management, hospitalization) and indirect (sick-leave days) cost reduction.

\section{Conclusion: optimal usage, place in therapy, and future perspectives}

Based on the accessible literature, NAC in COPD has been studied mostly at rather low dosages with variable outcomes. The short-term, low-dose studies suggest that NAC may not be a drug of choice to enhance the GSH antioxidant potential of the lungs, since the effects are poor. While its effect on the oxidative stress markers seems to be influenced even at low dosages, the higher doses may ensure more rapid response. On the other hand, even long-term administration at low doses does not always have the anti-inflammatory potential but substantially higher doses are necessary as in vitro studies have already demonstrated. As far as exacerbation rate, the number of sick-leave days and quality of life are concerned; the use of NAC seems to be promising as the majority of studies give favorable reports even at $600 \mathrm{mg} /$ day dose.

Because of the fact that higher doses seem to be more effective in inflammation and oxidative stress modulation with little side-effects, a change in the administration pattern may be of importance.

Furthermore, evaluating novel methods of drug delivery (inhaled NAC) (Szkudlarek et al 2004) and use of NAC derivatives with better bioavailability may result in more effective treatment. For example, Nacystelyn (NAL), a lysine salt of NAC, has mucolytic and antioxidant properties. Its mucolytic activity is approximately equal to the sum of the activities of its two components, namely acetylcysteine and lysine, and its antioxidant properties are comparable with those of NAC (Van Antwerpen et al 2005). Moreover, because of its neutral $\mathrm{pH}, \mathrm{NAC}$ can be delivered into the airways in inhaled form (Gillissen et al 1997; Antonicelli et al 2004). The inhaled form, tested in cystic fibrosis patients, was well tolerated and positively influenced airway mucus clearance (App et al 2002).

Another, newly developed form of NAC is N-acetylcysteine amide (NACA). Because of its neutral carboxyl group, NACA is lipophilic, cell permeating and has strong antioxidant and protective effects (Grinberg et al 2005). Nevertheless, more studies are necessary to assess the effectiveness of those derivatives in lung disorders in vivo. 


\section{References}

Adler KB, Hendley DD, Davis GS. 1986. Bacteria associated with obstructive pulmonary disease elaborate extracellular products that stimulate mucin secretion by explants of guinea pig airways. Am J Pathol, 125: $501-14$.

Anthonisen NR, Connett JE, Kiley JP, et al. 1994. Effects of smoking intervention and the use of an inhaled anticholinergic bronchodilator on the rate of decline of $\mathrm{FEV}_{1}$. The Lung Health Study. JAMA, 272:1497-505.

Antonelli-Inc, Imperiale C, Bellia V, et al. 2003. Do GOLD stages of COPD severity really correspond to differences in health status? Eur Respir J, 22:444-9.

Antonicelli F, Brown D, Parmentier M, et al. 2004. Regulation of LPSmediated inflammation in vivo and in vitro by the thiol antioxidant Nacystelyn. Am J Physiol Lung Cell Mol Physiol, 286:L1319-27.

App EM, Baran D, Dab I, et al. 2002. Dose-finding and 24-h moni-toring for efficacy and safety of aerosolized Nacystelyn in cystic fibrosis. Eur Respir J, 19:294-302.

Aruoma OI, Halliwell B, Hoey BM, et al. 1989. The antioxidant action of $\mathrm{N}$-acetylcysteine: its reaction with hydrogen peroxide, hydroxyl radical, superoxide, and hypochlorous acid. Free Radic Biol Med, 6:593-7.

Aylward M, Maddock J, Dewland P. 1980. Clinical evaluation of acetylcysteine in the treatment of patients with chronic obstructive bronchitis: a balanced double-blind trial with placebo control. Eur J Respir Dis Suppl, 111:81-9.

Benrahmoune M, Therond P, Abedinzadeh Z. 2000. The reaction of superoxide radical with $\mathrm{N}$-acetylcysteine. Free Radic Biol Med, 29:775-82.

Bhowmik A, Seemungal TAR, Sapsford RJ, et al. 2000. Relation of sputum inflammatory markers to symptoms and lung function changes in COPD exacerbations. Thorax, 55:114-20.

Black PN, Morgan-Day A, McMillan TE, et al. 2004. Randomised, controlled trial of $\mathrm{N}$-acetylcysteine for treatment of acute exacerbations of chronic obstructive pulmonary disease [ISRCTN21676344]. BMC Pulm Med, 4:13.

Boman G, Backer U, Larsson S, et al. 1983. Oral acetylcysteine reduces exacerbation rate in chronic bronchitis: report of a trial organized by the Swedish Society for Pulmonary Diseases. Eur J Respir Dis, 64:405-15.

Borgstrom L, Kagedal B. 1990. Dose dependent pharmacokinetics of $\mathrm{N}$-acetylcysteine after oral dosing to man. Biopharm Drug Dispos, 11:131-6.

Breuer R, Christensen TG, Lucey EC, et al. 1987. An ultrastructural morphometric analysis of elastase-treated hamster bronchi shows discharge followed by progressive accumulation of secretory granules. Am Rev Respir Dis, 136:698-703.

Bridgeman MM, Marsden M, Selby C, et al. 1994. Effect of N-acetyl cysteine on the concentrations of thiols in plasma, bronchoalveolar lavage fluid, and lung tissue. Thorax, 49:670-5.

Burrows B, Earle RH. 1969. Course and prognosis of chronic obstructive lung disease. A prospective study of 200 patients. $N$ Engl J Med, 280:397-404.

Cantin A, Crystal RG. 1985. Oxidants, antioxidants and the pathogenesis of emphysema. Eur J Respir Dis Suppl, 139:7-17.

Celli BR, MacNee W, Agusti A, et al. 2004. Standards for the diagnosis and treatment of patients with COPD: a summary of the ATS/ERS position paper. Eur Respir J, 23:932-46.

Church DF, Pryor WA. 1985. Free-radical chemistry of cigarette smoke and its toxicological implications. Environ Health Perspect, 64:111-26.

Churg A, Zay K, Shay S, et al. 2002. Acute Cigarette Smoke-Induced Connective Tissue Breakdown Requires both Neutrophils and Macrophage Metalloelastase in Mice. Am J Respir Cell Mol Biol, 27:368-74.

Cohan VL, Scott AL, Dinarello CA, et al. 1991. Interleukin-1 is a mucus secretagogue. Cell Immunol, 136:425-34.
Cotgreave IA, Berggren M, Jones TW, et al. 1987. Gastrointestinal metabolism of $\mathrm{N}$-acetylcysteine in the rat, including an assay for sulfite in biological systems. Biopharm Drug Dispos, 8:377-86.

Cotgreave IA, Eklund A, Larsson K, et al. 1987. No penetration of orally administered $\mathrm{N}$-acetylcysteine into bronchoalveolar lavage fluid. Eur $J$ Respir Dis, 70:73-7.

Crouch BI, Rusho WJ. 2005. Intravenous administration of N-Acetylcysteine. Ann Emerg Med, 46:207.

De Benedetto F, Aceto A, Dragani B, et al. 2005. Long-term oral N-acetylcysteine reduces exhaled hydrogen peroxide in stable COPD. Pulm Pharmacol Ther, 18:41-7.

De Caro L, Ghizzi A, Costa R, et al. 1989. Pharmacokinetics and bioavailability of oral acetylcysteine in healthy volunteers. Arzneimittelforschung, 39:382-6.

Decramer M, Rutten-Van Molken M, Dekhuijzen P, et al. 2005. Effects of NAC on outcome of COPD. The bronchitis randomized on NAC costutility study (BRONCHUS). Lancet, in press.

Dekhuijzen PN, Aben KK, Dekker I, et al. 1996. Increased exhalation of hydrogen peroxide in patients with stable and unstable chronic obstructive pulmonary disease. Am J Respir Crit Care Med, 154:813-16.

Desaki M, Takizawa H, Kasama T, et al. 2000. Nuclear factor-kappa b activation in silica-induced interleukin 8 production by human bronchial epithelial cells. Cytokine, 12:1257-60.

Donaldson GC, Seemungal TA, Bhowmik A, et al. 2002. Relationship between exacerbation frequency and lung function decline in chronic obstructive pulmonary disease. Thorax, 57:847-52.

Drost EM, Skwarski KM, Sauleda J, et al. 2005. Oxidative stress and airway inflammation in severe exacerbations of COPD. Thorax, 60:293-300.

Erzurum SC, Danel C, Gillissen A, et al. 1993. In vivo antioxidant gene expression in human airway epithelium of normal individuals exposed to $100 \% \mathrm{O}_{2} . J \mathrm{Appl}$ Physiol, 75:1256-62.

Fan VS, Curtis JR, Tu SP, et al. 2002. Using quality of life to predict hospitalization and mortality in patients with obstructive lung diseases. Chest, 122:429-36.

Fulghesu AM, Ciampelli M, Muzj G, et al. 2002. N-acetyl-cysteine treatment improves insulin sensitivity in women with polycystic ovary syndrome. Fertil Steril, 77:1128-35.

Gerrits CM, Herings RM, Leufkens HG, et al. 2003. N-acetylcysteine reduces the risk of re-hospitalisation among patients with chronic obstructive pulmonary disease. Eur Respir J, 21:795-8.

Gillissen A, Jaworska M, Orth M, et al. 1997. Nacystelyn, a novel lysine salt of $\mathrm{N}$-acetylcysteine, to augment cellular antioxidant defence in vitro. Respir Med, 91:159-68.

Gollub EG, Goswami SK, Sperber K, et al. 1992. Isolation and characterization of a macrophage-derived high molecular weight protein involved in the regulation of mucus-like glycoconjugate secretion. J Allergy Clin Immunol, 89:696-702.

Granjean EM, Berthet PH, Ruffmann R, et al. 2000. Cost-effectiveness analysis of oral NAC as preventive treatment in chronic bronchitis. Pharmacol Res, 42:39-50.

Grinberg L, Fibach E, Amer J, et al. 2005. N-acetylcysteine amide, a novel cell-permeating thiol, restores cellular glutathione and protects human red blood cells from oxidative stress. Free Radic Biol Med, 38:136-45.

Gudmundsson G, Gislason T, Janson C, et al. 2005. Risk factors for rehospitalisation in COPD: role of health status, anxiety and depression. Eur Respir J, 26:414-19.

Hajiro T, Nishimura K, Tsukino M, et al. 1999. A comparison of the level of dyspnea vs disease severity in indicating the health-related quality of life of patients with COPD. Chest, 116:1632-7.

Hansen NC, Skriver A, Brorsen-Riis L, et al. 1994. Orally administered $\mathrm{N}$-acetylcysteine may improve general well-being in patients with mild chronic bronchitis. Respir Med, 88:531-5.

Hogg PJ. 2004. Pathophysiology of airflow limitation in chronic obstructive pulmonary disease. Lancet, 364:709-21. 
Hoppe G, Chai YC, Sears J. 2003. Endogenous oxidoreductase expression is induced by aminoglycosides. Arch Biochem Biophys, 414:19-23.

Hutter D, Greene JJ. 2000. Influence of the cellular redox state on NF-kappaB-regulated gene expression. J Cell Physiol, 183:45-52.

Huynh HQ, Couper RT, Tran CD, et al. 2004. N-acetylcysteine, a novel treatment for Helicobacter pylori infection. Dig Dis Sci, 49:1853-61.

Jackson IM, Barnes J, Cooksey P. 1984. Efficacy and tolerability of oral acetylcysteine (Fabrol) in chronic bronchitis: a double-blind placebo controlled study. J Int Med Res, 12:198-206.

Jeffery PK, Li D. 1997. Airway mucosa: secretory cells, mucus and mucin genes. Eur Respir J, 10:1655-62.

Jones PW, Baveystock CM, Littlejohns P. 1989. Relationships between general health measured with the sickness impact profile and respiratory symptoms, physiological measures, and mood in patients with chronic airflow limitation. Am Rev Respir Dis, 140:1538-43.

Kasielski M, Nowak D. 2001. Long-term administration of $\mathrm{N}$-acetylcysteine decreases hydrogen peroxide exhalation in subjects with chronic obstructive pulmonary disease. Respir Med, 95:448-56.

Kelly GS. 1998. Clinical applications of N-acetylcysteine. Altern Med Rev, 3:114-27.

Kim S, Nadel JA. 2004. Role of neutrophils in mucus hypersecretion in COPD and implications for therapy. Treat Respir Med, 3:147-59.

King M, Rubin BK. 2002. Pharmacological approaches to discovery and development of new mucolytic agents. Adv Drug Deliv Rev, 54:1475-90.

Koechlin C, Couillard A, Cristol JP, et al. 2004. Does systemic inflammation trigger local exercise-induced oxidative stress in COPD? Eur Respir J, 23:538-44.

Koo MW, Ogle CW, Cho CH. 1986. Effects of verapamil, carbenoxolone and $\mathrm{N}$-acetylcysteine on gastric wall mucus and ulceration in stressed rats. Pharmacology, 32:326-34.

Lappas M, Permezel M, Rice GE. 2003. N-acetylcysteine inhibits phospholipid metabolism, proinflammatory cytokine release, protease activity and nuclear factor- $\mathrm{\kappa B}$ deoxyribonucleic acid-binding activity in human fetal membranes in vitro. J Clin Enocrinol Metab, 88:1723-9.

Livingstone CR, Andrews MA, Jenkins SM, et al. 1990. Model systems for the evaluation of mucolytic drugs: acetylcysteine and S-carboxymethylcysteine. J Pharm Pharmacol, 42:73-8.

Lundgren JD, Shelhamer JH. 1990. Pathogenesis of airway mucus hypersecretion. J Allergy Clin Immunol, 85:399-417.

MacNee W. 2000. Oxidants/antioxidants and COPD. Chest, 117:303 S-17S.

Matthews JR, Wakasugi N, Virelizier JL, et al. 1992. Thioredoxin regulates the DNA binding activity of NF-kappa B by reduction of a disulphide bond involving cysteine 62. Nucleic Acids Res, 20:3821-30.

Matuszczak Y, Farid M, Jones J, et al. 2005. Effects of N-acetylcysteine on glutathione oxidation and fatigue during handgrip exercise. Muscle Nerve, 32:633-8.

Maziak W, Loukides S, Culpitt S, et al. 1998. Exhaled nitric oxide in chronic obstructive pulmonary disease. Am J Respir Crit Care Med, 157:998-1002.

Medved I, Brown MJ, Bjorksten AR, et al. 2004. NAC enhances muscle cysteine and glutathione availability and attenuates fatigue during prolonged exercise in endurance-trained individuals. $J$ Appl Physiol, 97:1477-85.

Medved I, Brown MJ, Bjorksten AR, et al. 2003. N-acetylcysteine infusion alters blood redox status but not time to fatigue during intense exercise in humans. J Appl Physiol, 94:1572-82.

Nakamura H, Yoshimura K, McElvaney NG, et al. 1996. Netrophil elastase in respiratory epithelial lining fluid of individuals with cystic fibrosis induces IL-8 gene expression in a human bronchilal epithelial cells. $J$ Clin Invest, 89:1478-84.

Niederman MS, McCombs JS, Unger AN, et al. 1999. Treatment cost of acute exacerbations of chronic bronchitis. Clin Ther, 21:576-91.

Noguera A, Busquets X, Sauleda J, et al. 1998. Expression of adhesion molecules and $\mathrm{G}$ proteins in circulating neutrophils in chronic obstructive pulmonary disease. Am J Respir Crit Care Med, 158:1664-8.
Oostenbrink JB, Rutten-van Molken MP. 2004. Resource use and risk factors in high-cost exacerbations of COPD. Respir Med, 98:883-91.

Parr GD, Huitson A. 1987. Oral Fabrol (oral N-acetyl-cysteine) in chronic bronchitis. Br J Dis Chest, 81:341-8.

Patel IS, Seemungal TA, Wilks M, et al. 2002. Relationship between bacterial colonisation and the frequency, character, and severity of COPD exacerbations. Thorax, 57:759-64.

Pauwels RA, Buist AS, Calverly PMA, et al. 2001. Global strategy for the diagnosis, management, and prevention of chronic obstructive pulmonary disease. NHLBI/WHO Global Initiative for Chronic Obstructive Lung Disease (GOLD) workshop summary. Am J Respir Crit Care Med, 163:1256-76.

Pela R, Calcagni AM, Subiaco S, et al. 1999. N-acetylcysteine reduces the exacerbation rate in patients with moderate to severe COPD. Respiration, 66:495-500.

Peltoniemi M, Kaarteenaho-Wiik R, Saily M, et al. 2004. Expression of glutaredoxin is highly cell specific in human lung and is decreased by transforming growth factor-beta in vitro and in interstitial lung diseases in vivo. Hum Pathol, 35:1000-7.

Poole PJ, Black PN. 2003. Preventing exacerbations of chronic bronchitis and COPD: therapeutic potential of mucolytic agents. Am J Respir Med, 2:367-70.

Prescott LF, Donovan JW, Jarvie DR, et al. 1989. The disposition and kinetics of intravenous $\mathrm{N}$-acetylcysteine in patients with paracetamol overdosage. Eur J Clin Pharmacol, 37:501-6.

Rahman I, Morrison D, Donaldson K, et al. 1996. Systemic oxidative stress in asthma, COPD, and smokers. Am J Respir Crit Care Med, 154:1055-60.

Rasmussen JB, Glennow C. 1988. Reduction in days of illness after longterm treatment with $\mathrm{N}$-acetylcysteine controlled-release tablets in patients with chronic bronchitis. Eur Respir J, 1:351-5.

Reid M, Stokic DS, Koch SM, et al. 1994. NAC inhibits muscle fatigue in humans. J Clin Invest, 94:2468-74.

Robinson NP, Kyle H, Webber SE, et al. 1989. Electrolyte and other chemical concentrations in tracheal airway surface liquid and mucus. $J$ Appl Physiol, 66:2129-35.

Sadowska AM, Manuel YK, De Backer WA. 2007. Antioxidant and antiinflammatory efficacy of NAC in the treatment of COPD: Discordant in vitro and in vivo dose-effects: A review. Pulm Pharmacol Ther, 20:9-22.

Sadowska AM, Manuel YK, Vertongen T, et al. 2006. Effect of $\mathrm{N}$-acetylcysteine on neutrophil activation markers in healthy volunteers: In vivo and in vitro study. Pharmacol Res, 53:216-25.

Sadowska AM, van Overveld FJ, Gorecka D, et al. 2005. The interrelationship between markers of inflammation and oxidative stress in chronic obstructive pulmonary disease: modulation by inhaled steroids and antioxidant. Respir Med, 99:141-9.

Seemungal TA, Donaldson GC, Paul EA, et al. 1998. Effect of exacerbation on quality of life in patients with chronic obstructive pulmonary disease. Am J Respir Crit Care Med 157:1418-22.

Sen CK, Rankinen T, Vaisanen S, et al. 1994. Oxidative stress after human exercise: effect of $\mathrm{N}$-acetylcysteine supplementation. J Appl Physiol, 76:2570-7.

Siafakas NM, Vermeire P, Pride NB, et al. 1995. Optimal assessment and management of chronic obstructive pulmonary disease (COPD). The European Respiratory Society Task Force. Eur Respir J, 8:1398-420.

Snider GL, Lucey EC, Christensen TG, et al. 1984. Emphysema and bronchial secretory cell metaplasia induced in hamsters by human neutrophil products. Am Rev Respir Dis, 129:155-60.

Song JJ, Rhee JG, Suntharalingam M, et al. 2002. Role of glutaredoxin in metabolic oxidative stress. Glutaredoxin as a sensor of oxidative stress mediated by $\mathrm{H}_{2} \mathrm{O}_{2}$. J Biol Chem, 277:46566-75.

Stahl E, Lindberg A, Jansson SA, et al. 2005. Health-related quality of life is related to COPD disease severity. Health Qual Life Outcomes, $3: 56$ 
Stanescu D, Sanna A, Veriter C, et al. 1996. Airways obstruction, chronic expectoration, and rapid decline of $\mathrm{FEV}_{1}$ in smokers are associated with increased levels of sputum neutrophils. Thorax, 51:267-71.

Stey C, Steurer J, Bachmann S, et al. 2000. The effect of oral NACin chronic bronchitis: a quantitative systematic review. Eur Respir J, 16:253-62.

Szkudlarek U, Zdziechowski A, Witkowski K, et al. 2004. Effect of inhaled $\mathrm{N}$-acetylcysteine on hydrogen peroxide exhalation in healthy subjects. Pulm Pharmacol Ther, 17:155-62.

Takeyama K, Dabbagh K, Lee HM, et al. 1999. Epidermal growth factor system regulates mucin production in airways. Proc Natl Acad Sci U $S A, 96: 3081-6$.

Tattersall AB, Bridgman KM, Huitson A. 1984. Irish general practice study of acetylcysteine (Fabrol) in chronic bronchitis. J Int Med Res, 12:96-101.

Tenenbein M. 1984. Hypersensitivity-like reactions to N-acetylcysteine. Vet Hum Toxicol, 26(Suppl 2):3-5.

Tsikas D, Sandmann J, Ikic M, et al. 1998. Analysis of cysteine and $\mathrm{N}$-acetylcysteine in human plasma by high-performance liquid chromatography at the basal state and after oral administration of $\mathrm{N}$-acetylcysteine. J Chromatogr B Biomed Sci Appl, 708:55-60.

Urban T, Akerlund B, Jarstrand C, et al. 1997. Neutrophil function and glutathione-peroxidase (GSH-px) activity in healthy individuals after treatment with N-acetyl-L-cysteine. Biomed Pharmacother, 51:388-90.

Van Antwerpen P, Boudjeltia KZ, Bavar S, et al. 2005. Thiol containing molecules interact with $\mathrm{MPO} / \mathrm{H}_{2} \mathrm{O}_{2} /$ chloride system to inhibit LDL oxidation. Biochem Biophys Res Commun, 337:82-8.

van Overveld FJ, Demkow U, Gorecka D, et al. 2005. New developments in the treatment of COPD: comparing the effects of inhaled corticosteroids and N-acetylcysteine. J Physiol Pharmacol, 56(Suppl 4):135-42. van Overveld FJ, Vermeire PA, De Backer WA. 2000. Induced sputum of patients with chronic obstructive pulmonary disease (COPD) contains adhesion-promoting, therapy-sensitive factors. Inflamm Res, 49:8-13.

Ventresca GP, Cicchetti Ferrari, Braga PC, et al. 1989. Drugs in bronchial mucology. New York: Raven Pr, pp 77-102.

Verrill D, Barton C, Beasley W, et al. 2005. The effects of short-term and long-term pulmonary rehabilitation on functional capacity, perceived dyspnea, and quality of life. Chest, 128:673-83.

Vestbo J, Prescott E, Lange P. 1996. Association of chronic mucus hypersecretion with $\mathrm{FEV}_{1}$ decline and chronic obstructive pulmonary disease morbidity. Copenhagen City Heart Study Group. Am J Respir Crit Care Med, 153:1530-5.

Wedzicha JA, Donaldson GC. 2003. Exacerbations of chronic obstructive pulmonary disease. Respir Care, 48:1204-13.

Wilkinson TM, Patel IS, Wilks M, et al. 2003. Airway bacterial load and $\mathrm{FEV}_{1}$ decline in patients with chronic obstructive pulmonary disease. Am J Respir Crit Care Med, 167:1090-5.

Wolkove N, Dajczman E, Colacone A, et al. 1989. The relationship between pulmonary function and dyspnea in obstructive lung disease. Chest, 96:1247-51.

Wuyts WA, Vanaudenaerde BM, Dupont LJ, et al. 2003. Involvement of p38 MAPK, JNK, p42/p44 ERK and NF-kappaB in IL-1beta-induced chemokine release in human airway smooth muscle cells. Respir Med, 97:811-17.

Zafarullah M, Li WQ, Sylvester J, et al. 2003. Molecular mechanisms of N-acetylcysteine actions. Cell Mol Life Sci 2003:60:6-20.

ZuWallack RL, Haggerty MC, Jones P. Clinically meaningful outcomes in patients with chronic obstructive pulmonary disease. Am $\mathrm{J} \mathrm{Med}$, 117(Suppl 12A):49S-59S. 